\title{
Numerical predictions of sand erosion in a choke valve
}

\author{
N. H. Saeid \\ Mechanical Engineering Programme, Universiti Teknologi Brunei, \\ Jalan Tungku Link, Gadong BE 1410 \\ Brunei Darussalam \\ E-mail: nawaf.saeid@utb.edu.bn \\ Phone: +6732461020; Fax: +673-2461035
}

\begin{abstract}
Two-phase turbulent flow of crude oil and sand in a choke valve is analysed in the present article using 3D computational fluid dynamics simulations. The discrete phase mathematical model is used to simulate the sand flow and its interaction with the oil flow in the system. Parametric study is done to identify the governing parameters to minimize the sand erosion in the system. The valve geometry and dimensions are taken from an industrial oil production project. The parameter considered in the present study are the percentage valve opening, flow rate of the sand and the pressure difference between the inlet and outlet pipes. The simulation results are presented to show the erosion rate variation with the valve opening, sand flow rate and the pressure difference. It is found that the erosion rate is high for small valve opening as well as large valve opening. Minimum erosion rate is found when the valve opening is between $20-30 \%$ for all the cases with various pressure differences. Locations of maximum erosion rate are predicted in the simulations.
\end{abstract}

Keywords: Sand erosion; choke valve; CFD simulations; discrete phase model; turbulent flow.

\section{INTRODUCTION}

Sand erosion, due to the impact of sand particles carried by crude oil on the system walls, leads to considerable damage to the critical components of transport and processing equipment, such as valves. Sand entrained in the crude oil impinge the surfaces of piping and control valves causing in removal of surface material. It is important in risk management of the oil production/processing equipment to predict the rate of erosion damages accurately. Similar to corrosion [1,2], sand erosion is a complicated process, depends on many parameters, such as: sand properties and particle tracks, fluid flow, surface conditioning and multi-phase effects among others.

The literature review shows a vast use of computational fluid dynamics (CFD) techniques in predicting sand erosion in the oil and gas applications. CFD modeling can predict the detailed information on the location and the rate of erosion. The results of the CFD modeling have the potential to optimize the design prior to fabrication and testing. The literature shows many erosion models using either single phase or multi-phase modeling. The 
simple and easy to employ sand erosion model is using the Discrete Phase Model (DPM), which applicable for sand volume fractions < $10 \%$. Meng and Ludema [3] reviewed of the erosion models developed to predict the erosion rate. They identified the parameters affecting the eroded material of a surface and the erosion process. The review showed that each model was the result of a specific and individual method, and reliance on experimental data will always be necessary in the erosion modeling. More recently, Paul and Mohamed [4] presented a review on the erosion-corrosion in oil and gas applications. The study highlighted that dominant mechanisms that occur in the erosion-corrosion process is significantly influenced by the operating parameters and environmental conditions. Parsi et. al. [5] presented a detailed review of sand particle erosion for oil and gas applications. The authors described the important factors affecting erosion and reviews the recent erosion models. The erosion modeling using CFD is discussed as well. Wang and Shirazi [6] investigated numerically the sand erosion for elbows and bends. Their results proved that a large elbow curvature has smaller angles of impingement than those in a shorter radius bend. Therefore, the erosion rate is observed to be lower in the case of a large elbow compare to the short radius bends. Mazumder et al [7] developed a model that predicts solid particle wear of elbows due to erosion with annular flow of three phases (gas-liquid-solid). A CFD study based on DPM is performed by Elsaadawy et al. [8] for black powder erosion of a gas pipeline ball control valve. Their results show that the erosion rate critical areas, were on the inside wall of the ball directly downstream of the inlet, and on the wall just before the outlet on the body. They recommended to use Stellite 12 instead of A-105 carbon steel and A-505 carbon steels to reduce the erosion rate of the valve. Forder et al. [9] used CFD to investigate the sand erosion problem in a choke valve. The study concluded that reduction in erosion rate could be achieved by changing the design of the choke valve. Wallace et al. [10] simulated a simplified model of a choke valve and then considered a more complex geometry model. Their results for the erosion rates were $60 \%$ lower than experimental data for the simplified model; in case of the complex valve geometry, the calculated erosion rates were 10-15 times lower than the experimental measurements. Paggiaro et al. [11] used CFD method to study the sand erosion in choke valves. The simulation results presented and compared with experimental measurements with good agreement for the flow characteristics and hot spots of sand erosion. However, the erosion rates result from the simulations were underestimated. The aims of the current study are to simulate the crude oil flow in a real plug and cage choke valve used in the oil production project. The study will include parametric study to identify the governing parameters effecting the sand erosion in the valve in order to minimize the damage in the system.

\section{MATHEMATICAL MODEL}

The inlet and outlet pipes are 6 in diameters and normal to each other in the system. The choke valve is located in-between. The choke valve used in the present investigations is shown in Figure 1. The piston is the main part of the valve which is used to control the flow by closing/opening the holes on the valve cage. 
The inlet pipe length is extended to be $12 d_{\text {pipe }}$ in order to eliminate the effects of the boundary layers entrance region and ensure the fully developed flow at the valve inlet. Similarly, the outlet pipe is extended to be $6 d_{\text {pipe }}$ to eliminate the effects of the reversed flow to the solution domain. The valve holes are generated with centre to centre distance of 0.5 in and each line of holes is rotated $30^{\circ}$ from the neighbour line of holes.

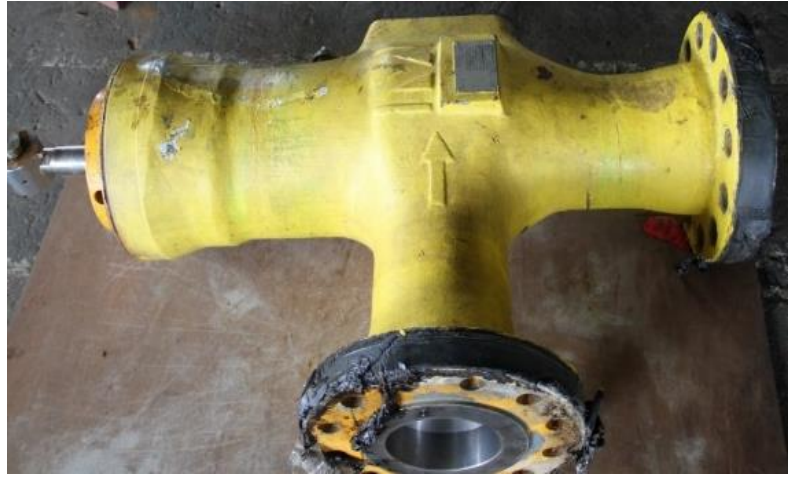

(a) Real crude oil choke valve

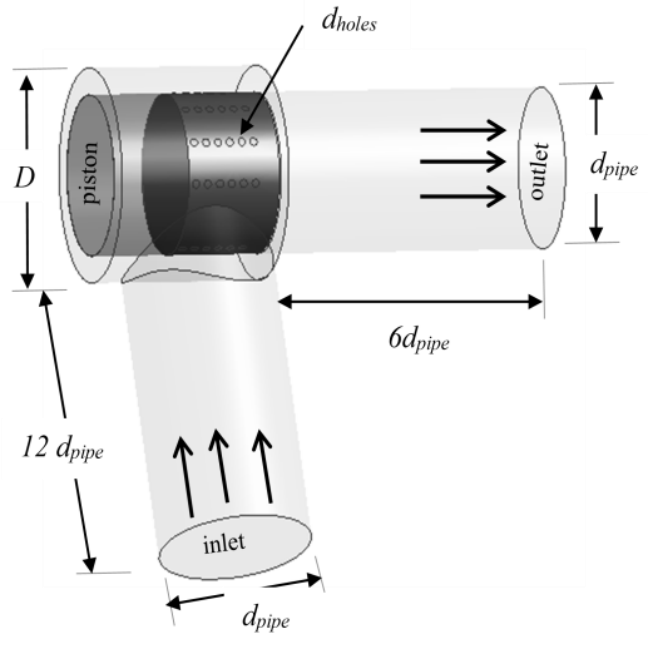

(b) physical model

Figure 1. Flow geometry $\left(D=8\right.$ in; $d_{\text {pipe }}=6$ in; $d_{\text {holes }}=0.3$ in $)$.

In the present analysis, the fluid phase is treated as continuous phase and the governing equations are based on the mass and momentum balance. The sand particles are treated as the dispersed phase, which can be modelled using the Discrete Phase Model (DPM). In DPM the solid particles must be at a low volume fraction (10-12\%). DPM computation starts with fluid flow field, after which the trajectories of sand particles are computed and finally the solution strategy will update the equations of the fluid phase for exchange mass and momentum between the two phases.

\section{Continuous phase}

The flow of the continuous phase (crude oil) is selected in the turbulent regime. The mass conservation (continuity) and the Reynolds-averaged (momentum conservation) NavierStokes (RANS) equations in Cartesian tensor form are [12]:

$$
\begin{gathered}
\frac{\partial}{\partial x_{i}}\left(\rho u_{i}\right)=0 \\
\frac{\partial}{\partial x_{j}}\left(\rho u_{i} u_{j}\right)=-\frac{\partial p}{\partial x_{i}}+\frac{\partial}{\partial x_{j}}\left\{\mu\left(\frac{\partial u_{i}}{\partial x_{j}}+\frac{\partial u_{j}}{\partial x_{i}}-\frac{2}{3} \delta_{i j} \frac{\partial u_{l}}{\partial x_{l}}\right)\right\}+\frac{\partial}{\partial x_{j}}\left(-\rho \overline{u_{l} \dot{u}_{\jmath}}\right)+S
\end{gathered}
$$

where $u_{i}$ and $\dot{u}_{i}$ are the average and fluctuating components of the velocity vector $(i=1,2$, 3 ) and the overbar represents the average value of the fluid velocity. The delta $\delta_{i j}=1$ if $i=$ $j$ and otherwise it is zero. $S$ is the momentum source term. The Reynolds-averaged method 
requires that the Reynolds stresses in Equation (2) be modelled. A popular method uses the Boussinesq approximation to relate the Reynolds stresses to the average velocity gradients:

$$
-\rho \overline{u_{\imath} \dot{u}_{j}}=\mu_{t}\left(\frac{\partial u_{i}}{\partial x_{j}}+\frac{\partial u_{j}}{\partial x_{i}}\right)-\frac{2}{3}\left(\rho k+\mu_{t} \frac{\partial u_{k}}{\partial x_{k}}\right) \delta_{i j}
$$

where the eddy viscosity $\left(\mu_{t}\right)$ calculation depends on the turbulence model and $k$ is the turbulent kinetic energy of the flow. In the present study, two turbulence models are used. They are the realizable $k-\varepsilon$ with scalable wall functions [13] and the SST $k-\omega$ with near surface wall corrections model [14]. The effects of the turbulence models are tested and the results are discussed in the validation section.

\section{Discrete phase}

The discrete phase model is employed, in which the particle trajectories are calculated through the solution domain. Along these trajectories, the real mass flow of particles is accounted for. In this way, the momentum exchange between particles and continuous phase can be made. However, the particles in DPM do not interact with each other. The calculation of trajectories is done by solving the force balance for a single particle using Newton's second law as follows [15]:

$$
\frac{d u_{p i}}{d t}=F_{D}\left(u_{i}-u_{p i}\right)+\frac{g_{i}\left(\rho_{p}-\rho\right)}{\rho_{p}}+F_{i}
$$

where $u_{p i}$ is the particle velocity vector in the $i$ direction and $\rho_{p}$ is the density of the particle. The buoyancy force term $g_{i}\left(\rho_{p}-\rho\right)$ is neglected in the present study as the sand particles and crude oil have insignificant difference in densities. $F_{i}$ is an additional acceleration of the fluid surrounding the particle, and $F_{D}$ is the drag force/ particle mass and $F_{i}$ is the force needed to accelerate/decelerate the fluid around the particle. These terms are defined by [15]:

$$
\begin{gathered}
F_{D}=\frac{18 \mu}{\rho_{p} d_{p}^{2}} \frac{C_{D} R e}{24} \\
F_{i}=\frac{1}{2} \frac{\rho}{\rho_{p}} \frac{d\left(u_{i}-u_{p i}\right)}{d t}
\end{gathered}
$$

where $\mu$ is the dynamic viscosity of the continuous phase (fluid), $d p$ is the diameter of the particle, and $R e$ is the Reynolds number, which is given by:

$$
R e=\frac{\rho d_{p}\left|u_{p i}-u_{i}\right|}{\mu}
$$

The drag coefficient $C_{D}$ in equation (5) for smooth spherical particles applicable for wide ranges of Re given by [16]: 


$$
C_{D}=a_{1}+\frac{a_{2}}{R e}+\frac{a_{3}}{R e^{2}}
$$

The default values of the model constants $\left(a_{1}, a_{2}\right.$ and $\left.a_{3}\right)$ are used in the present investigations [16]. The discrete random walk model is implemented in the present study to model the particle trajectories. The details of discrete random walk model can be found in FLUENT documentation [15]. The rate of erosion is defined as the velocity of the mass removal of material from a surface per unit area $\left(\mathrm{kg} / \mathrm{m}^{2} \mathrm{~s}\right)$. The aim of the current study is to monitor the particle erosion rate at wall boundaries, which is given in the following correlation [15]:

$$
R_{\text {erosion }}=\sum_{p=1}^{N_{\mathrm{p}}} \frac{\dot{m}_{p} C\left(d_{p}\right) f(\alpha) v^{b(v)}}{A_{\text {face }}}
$$

where $\dot{m}_{p}=$ mass flow rate of a particle $(\mathrm{kg} / \mathrm{s}), C\left(d_{p}\right)=$ particle diameter function, $f(\alpha)=$ impact angle function, $v=$ relative solid particle velocity, $b(v)=$ function of particle velocity and $A_{\text {face }}=$ area of the mesh face at the surface. Values of these functions for sand erosion of carbon steel and aluminum are found by Edwards [17]. The default values of $C\left(d_{p}\right)=$ $1.8 \times 10^{-9}, f(\alpha)=1$, and $b(v)=0$ are used in the present study.

\section{NUMERICAL SCHEME}

The geometry of the present problem has a symmetry as shown in Figure 2. Therefore, half of the geometry is considered as the computational domain. ANSYS software [16] is employed to generate and mesh the computational domain as shown in Figure 2 for the case of 50\% valve opening. Curvature size function [18] is used to generate the mesh. Relatively small size of the mesh cells is generated in the valve holes and walls where five inflation layers are generated near walls. The mesh is then transferred to the solver, which is FLUENT software [15].

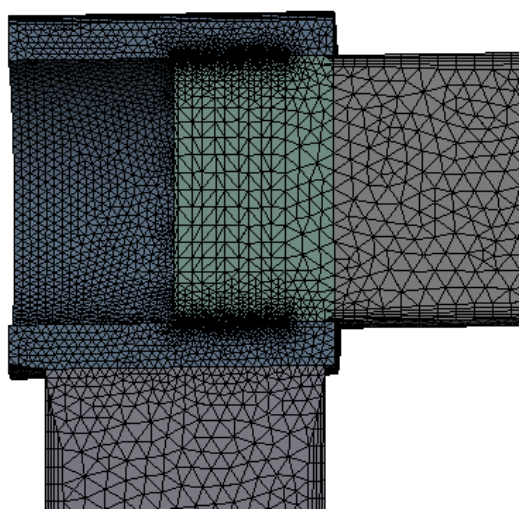

(a) symmetry plane

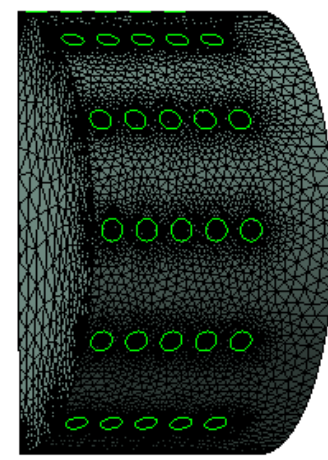

(b) valve holes

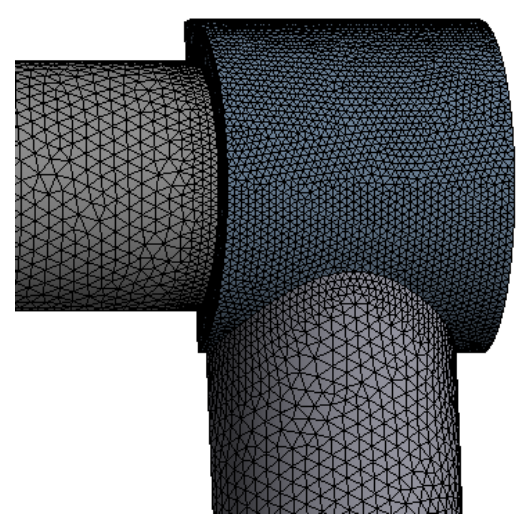

(c) exterier walls

Figure 2. Mesh details for $50 \%$ valve oppening (Total number of cells $=614587$ ). 
Crude oil with API (American Petroleum Institute) gravity of 21.9 is used as the working fluid and it is considered as incompressible Newtonian fluid with density $\rho=931.3 \mathrm{~kg} / \mathrm{m}^{3}$ and dynamic viscosity $\mu=0.0177 \mathrm{~kg} / \mathrm{ms}$ [19]. For waxy crude oil, refer to reference [20]. The sand material is considered as inert anthracite spherical particles with uniform diameter of $10^{-6} \mathrm{~m}$ with density of $1550 \mathrm{~kg} / \mathrm{m}^{3}$ injected from the inlet face with different mass flow rates.

The no-slip boundary condition is selected at all the solid surfaces of the system. The surfaces generated from the symmetry plane are set as symmetry plane. The boundary condition at the inlet is selected to be high gage pressure in the range $1000 \mathrm{kPa}$ to $3000 \mathrm{kPa}$ and the pressure at the outlet is set to atmospheric (zero gage). The boundary conditions for particles are set as reflected by the walls and escape through the inlet and outlet boundaries. In the present study, it is assumed that the turbulent intensity is $5 \%$ at the inlet and the backflow at the outlet for all the cases. The turbulent viscosity ratio is selected to be the default value of 10 for both the inlet flow and the backflow at the outlet [15].

The numerical solution of the governing equations is based on the second order upwind scheme. SIMPLE algorithm (Patankar 1980 [21]) is employed to solve the discretized equations. This is an iterative solution and needs under relaxation to control the changes in the values during iteration. The values of the under relaxation factors of $0.3,0.7$ and 0.8 for pressure, momentum and turbulence model equations respectively are used. The under relaxation factors of 0.5 is used for the interphase exchange of momentum during the calculation. The maximum residual in continuity equation and all variables were lower than $10^{-3}$ at the end of the iterations. The numerical solution of the Discrete Phase Model is computed by integrating equation (4) using the implicit Euler method [15].

\section{VALIDATION AND MESH SENSITIVITY ANALYSIS}

To the best of knowledge of the author, there are no experimental data for this problem. Therefore, the flow through this system can be used for validation by comparing the present result with the simple pipe flow. The velocity profile of a single-phase flow (crude oil flow without sand) in the inlet pipe (at $0.15 \mathrm{~m}$ from the valve centre with inlet pressure of 2000 $\mathrm{kPa}$ ) is used for validation. The valve opening is selected in middle rage $50 \%$. The best known in the pipe flow is the power-law velocity profile express as [22]:

$$
\frac{u}{u_{\max }}=\left(1-\frac{r}{R}\right)^{1 / n}
$$

where $r$ is the radial distance from the centreline of the pipe and $R$ is the total radius of the pipe. The results are presented in Figure 3 for both numerical results generated using two turbulence models and empirical profiles at the inlet pipe. The results show that prediction using the realizable $k-\varepsilon$ with scalable wall functions is almost similar to that obtained using SST $k-\omega$ model. However, the solution is converged faster when the realizable $k-\varepsilon$ with scalable wall functions is used. Therefore the realizable $k-\varepsilon$ with scalable wall functions it is used for results generation in the present study. 
Different mesh sizes are used for grid independent study and the accuracy of the results is verified by checking the velocity profiles and mass balance of the flow using the realizable $k-\varepsilon$ with scalable wall functions. The total number of cells (control volumes) in the fine mesh is 815450 cell with $50 \%$ valve opening. The moderated mesh contains 614 587 cell and it is 487765 cell for the coarse mesh for the same geometry. The results presented in Figure 3 for the velocity profile in the inlet pipe show negligible difference using moderated and fine mesh sizes with same trend as the power law profile. However, the results generated using the coarse mesh show considerable difference with the power law profile. Therefore, the moderated size of the mesh is used to generate the results in the present study. The global mass balance is monitored and satisfied in the converged solution within $\pm 0.01 \%$ in all cases. For example, the mass balance is checked for crude oil flow enters the valve under $2000 \mathrm{kPa}$ with $50 \%$ valve opening. The results show that: mass flow rate at the inlet $=$ $52.387 \mathrm{~kg} / \mathrm{s}$, while mass flow rate at the outlet $=52.391 \mathrm{~kg} / \mathrm{s}$.

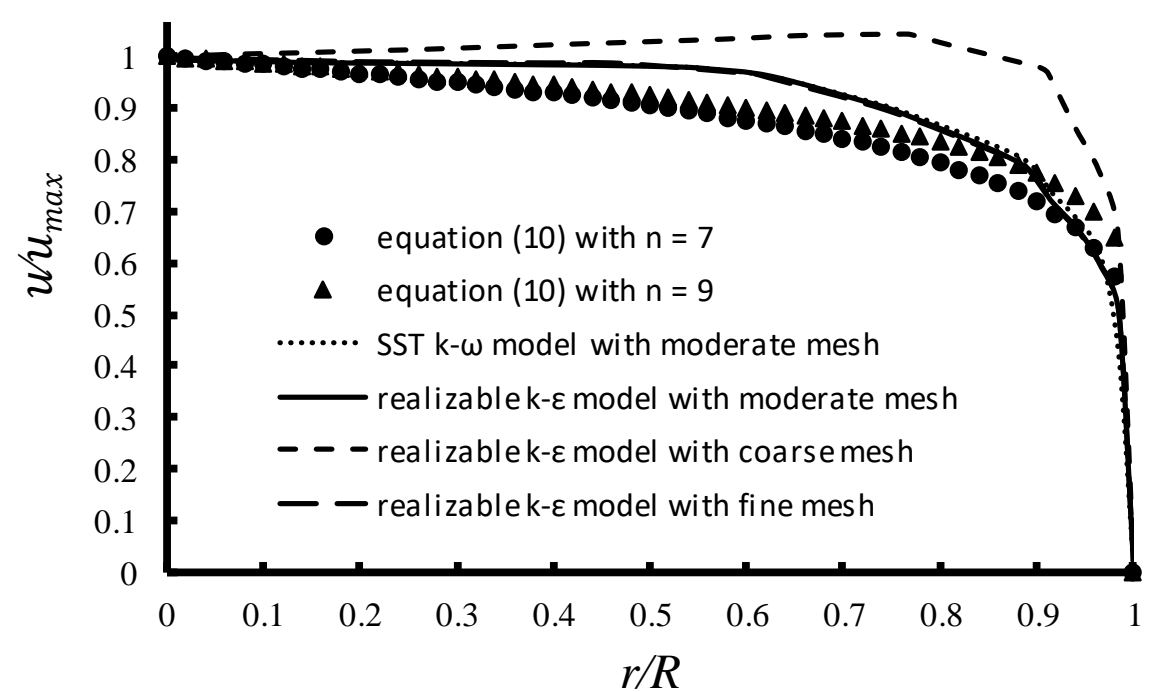

Figure 3. Velocity profiles with inlet pressure of $2000 \mathrm{kPa}$ and $50 \%$ valve opening.

\section{RESULTS AND DISCUSSION}

To understand the flow structure and the particles-fluid interaction and its effect on the surface erosion, the governing equations are solved and the erosion rate is calculated for different conditions of valve operation. Simulation results are shown in Figure 4 for the system with $50 \%$ valve opening under intermediateinlet pressure of $2000 \mathrm{kPa}$ with sand flow rate of $10^{-5} \mathrm{~kg} / \mathrm{s}$.

Figures $4 \mathrm{a}$ and $4 \mathrm{~b}$ show the classical relationship between the crude oil pressure and its velocity near the valve holes where the pressure dropping with increasing the velocity. Maximum velocity and minimum pressure were found when the crude oil is forced through the valve holes, where maximum velocity reaches to $70 \mathrm{~m} / \mathrm{s}$ in this case. Figure $4 \mathrm{c}$ shows the sand is dispersed and almost follow the crude oil streamlines with approximately similar velocity range. 
The sand particles trajectory impingement on the walls leads to erosion of the walls as shown in Figure 4d. The simulation results show high erosion rate when the flow changes the direction and the sand impinging on the walls, which is also reported by Parsi et al [5] and Mazumder [23] among others. Maximum sand erosion rate is observed in the zone where the valve is connected with the inlet pipe. Figure $4 \mathrm{~d}$ shows also that sand particles erodes the regions near the valve holes and piston edge.

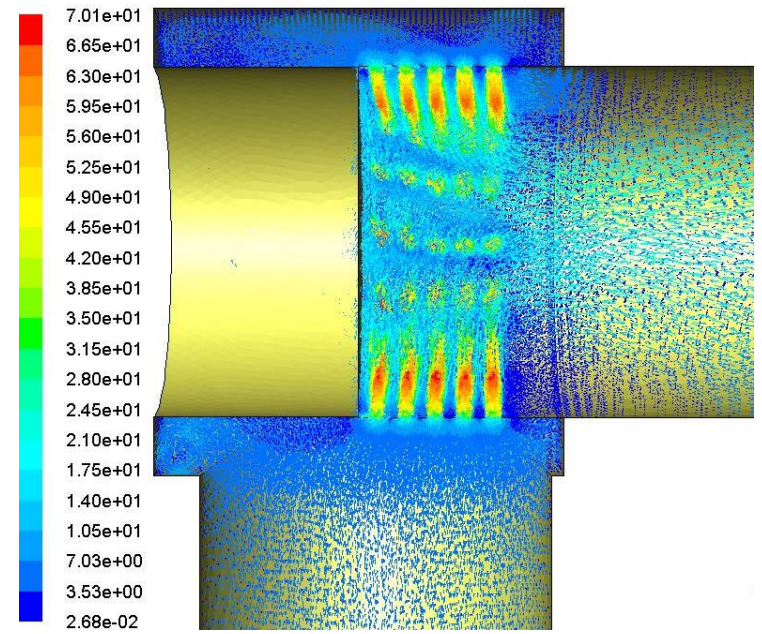

(a) velocity vectors $(\mathrm{m} / \mathrm{s})$

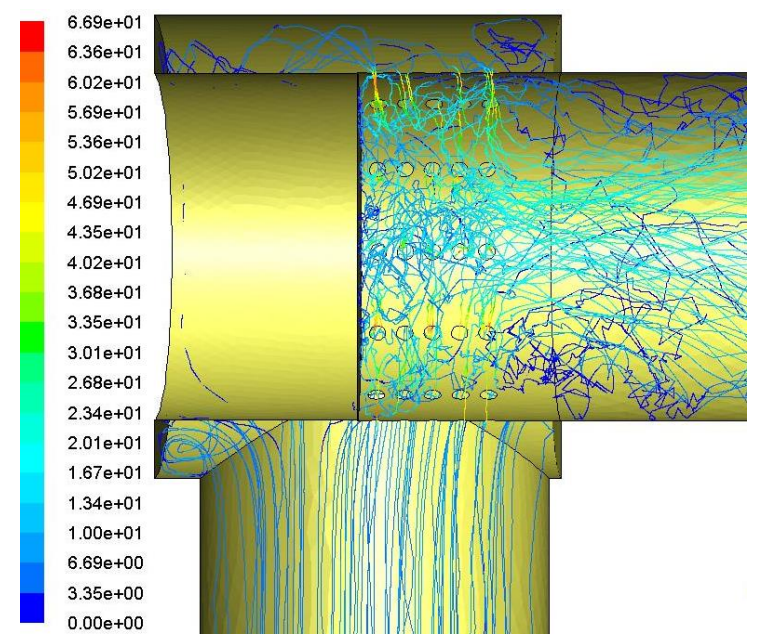

(c) particle tracking velocity $(\mathrm{m} / \mathrm{s})$

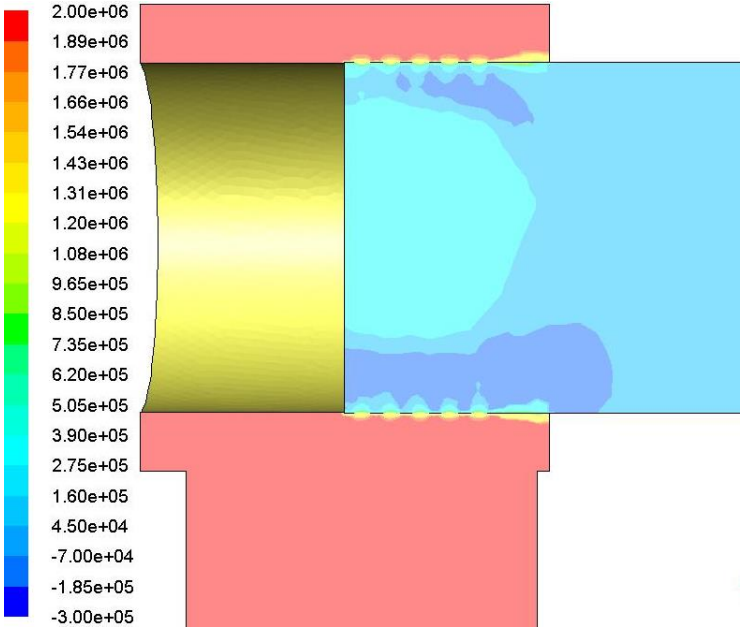

(b) pressure countours $(\mathrm{Pa})$

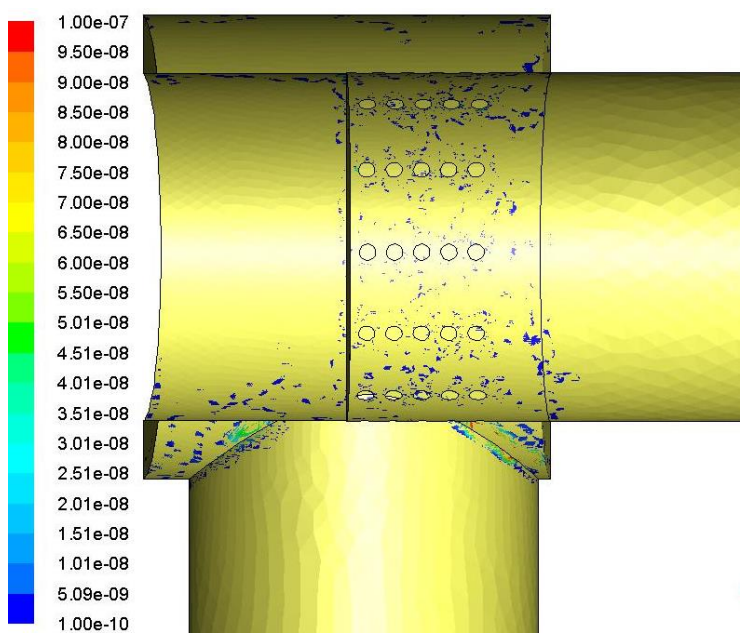

(d) erosion rate countours $\left(\mathrm{kg} / \mathrm{m}^{2} \mathrm{~s}\right)$

Figure 4. Simulation results with 50\% valve opening under inlet pressure of $2000 \mathrm{kPa}$ and sand flow rate of $10^{-5} \mathrm{~kg} / \mathrm{s}$.

The results are generated for different inlet pressure and percentage valve opening with constant sand properties and sand flow rate of $10^{-5} \mathrm{~kg} / \mathrm{s}$ using same methodology. The flow rate of the crude oil and the area-weighted average erosion rate of the valve walls and piston 
excluding the inlet and outlet pipes are calculated for various opening percentage of the valve. The results of the oil mass flow rate and the erosion rate are presented in Figures 5 and 6 respectively.

The crude oil mass flow rate is increasing by either increasing the valve opening or increasing the inlet pressure as shown in Figure 5. The simulation results show also the erosion rate increases with increasing the inlet pressure. However, the erosion rate decreases with increasing the valve opening from $10 \%$ to $20 \%$ or $30 \%$ as shown in Figure 6 . This trend is obvious with high inlet pressure as the jets formed from the flow through the valve opening are stronger (with higher velocities for both phases) when the inlet pressure is high. Opening the valve $30 \%$ and above leads to increase the erosion rate with increasing the valve opening due to higher velocities through the valve, which leads to increase the mass flow rate of the crude oil.

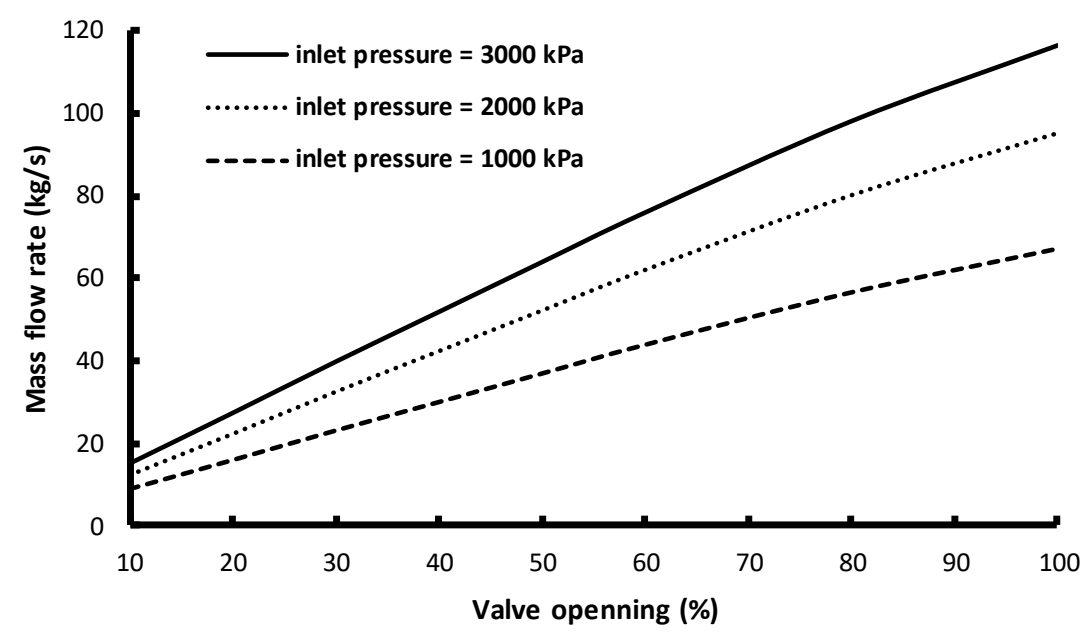

Figure 5. Variation of average mass flow rate with percentage valve openning with sand flow rate of $10^{-5} \mathrm{~kg} / \mathrm{s}$.

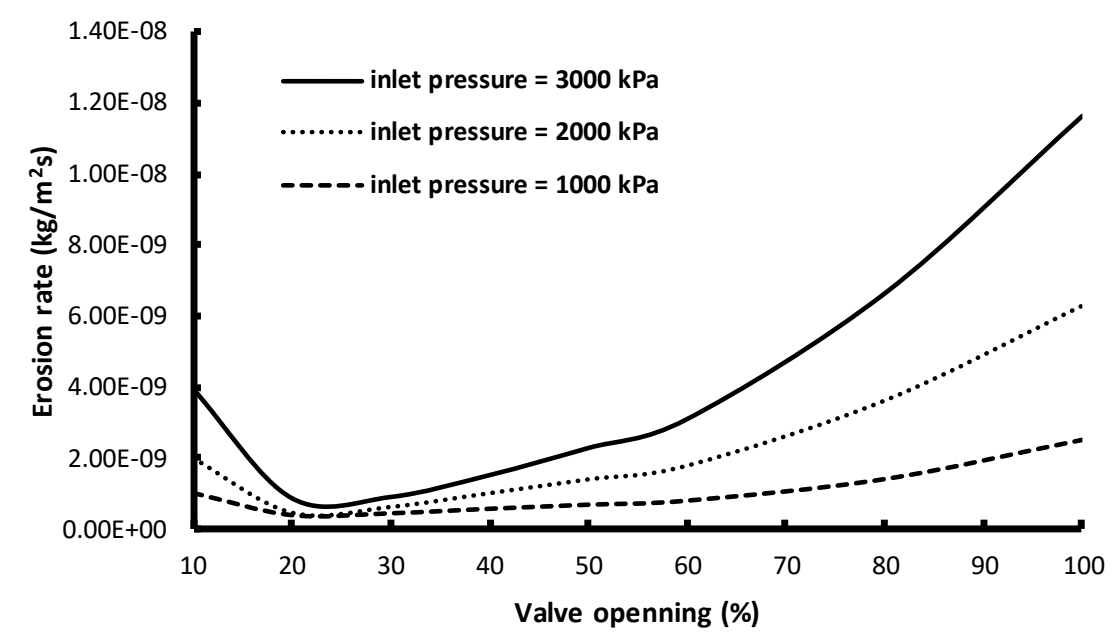

Figure 6. Variation of average erosion rate with percentage valve openning with sand flow rate of $10^{-5} \mathrm{~kg} / \mathrm{s}$. 
To show the effect of the mass flow rate of the sand on the erosion rate, the results are generated for different sand mass flow rate injected from the inlet face for the case of $60 \%$ valve opening. The variation of average erosion rate with particles mass flow rate are shown in Figure 7 with different values of the inlet pressure. The results presented in Figure 7 shows the linear relationship between the erosion rate and the particles mass flow rate. This is obvious as the model used in the present study (defined in equation (9)) assumes linear relationship between the erosion rate and the mass flow rate of the sand particles.

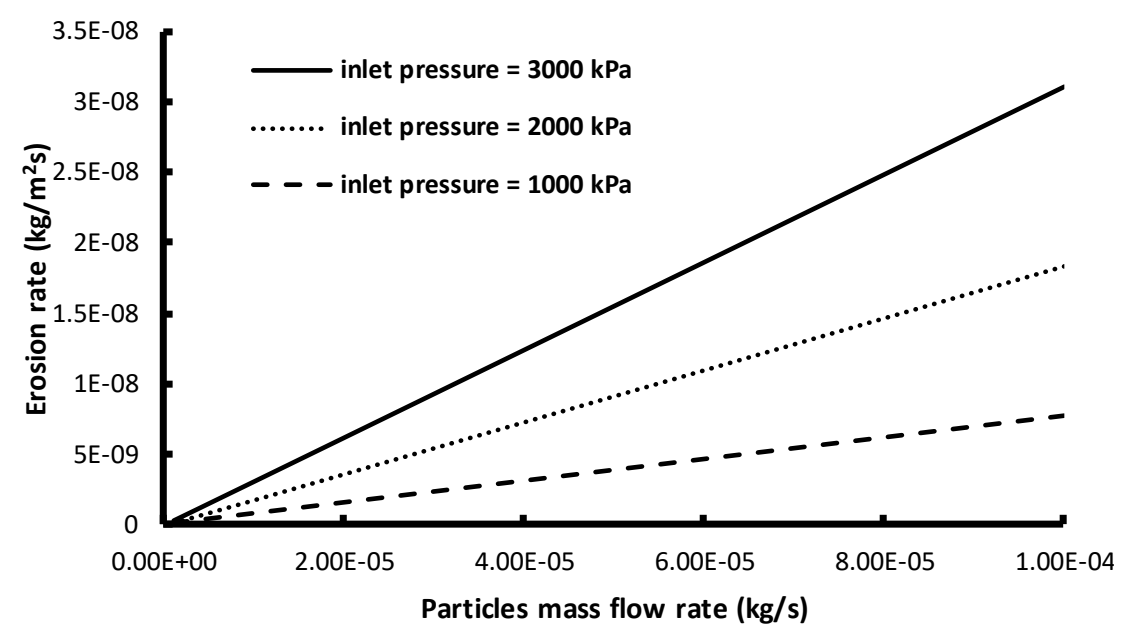

Figure 7. Variation of average erosion rate with particles mass flow rate for $60 \%$ valve opening.

Finally the contours for the sand erosion rates are presented in Figure 8 for different percentage of valve opening with inlet pressure of $3000 \mathrm{kPa}$ and sand flow rate of $10^{-5} \mathrm{~kg} / \mathrm{s}$. In order to compare the results, same rage for erosion rate is used for all cases as shown in Figure 8a-8f. Again, maximum sand erosion rate is observed for different valve opening in the zone where the valve is connected with the inlet pipe. All the cases presented in Figure 8 shows the regions near the valve holes and piston edge are effected by sand erosion where the flow changes the direction sharply which leads to sand impingement on the walls.
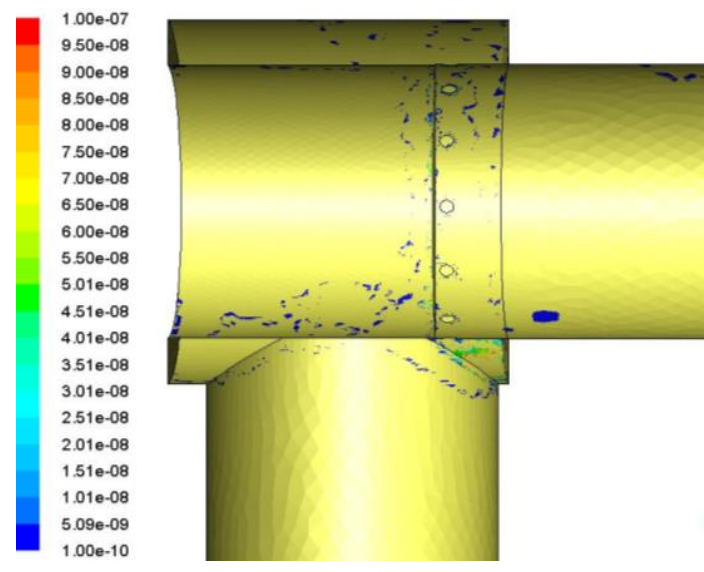

(a) valve opening $10 \%$

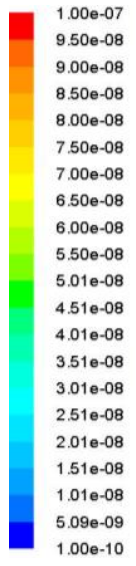

$.00 \mathrm{e}-10$

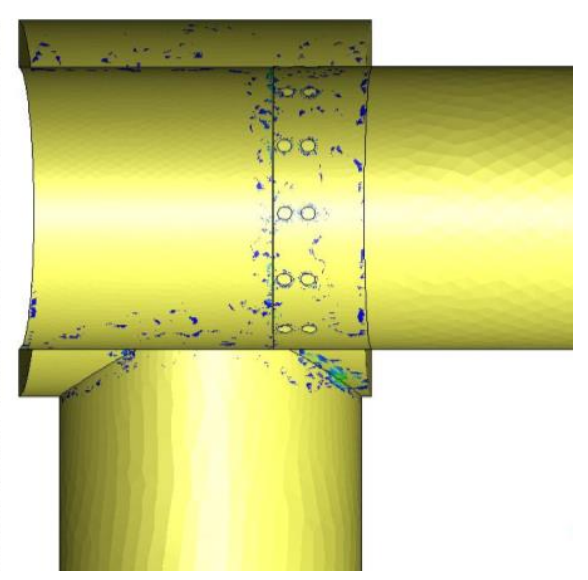

(a) valve opening $20 \%$ 

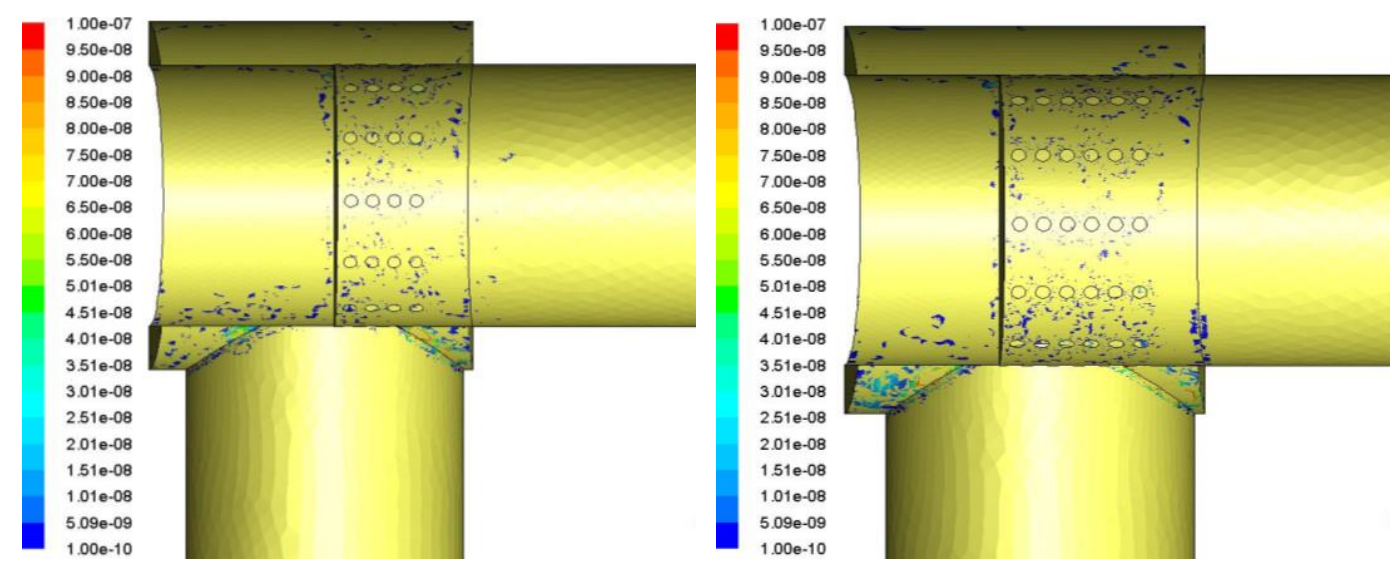

(c) valve opening $40 \%$

(d) valve opening $60 \%$
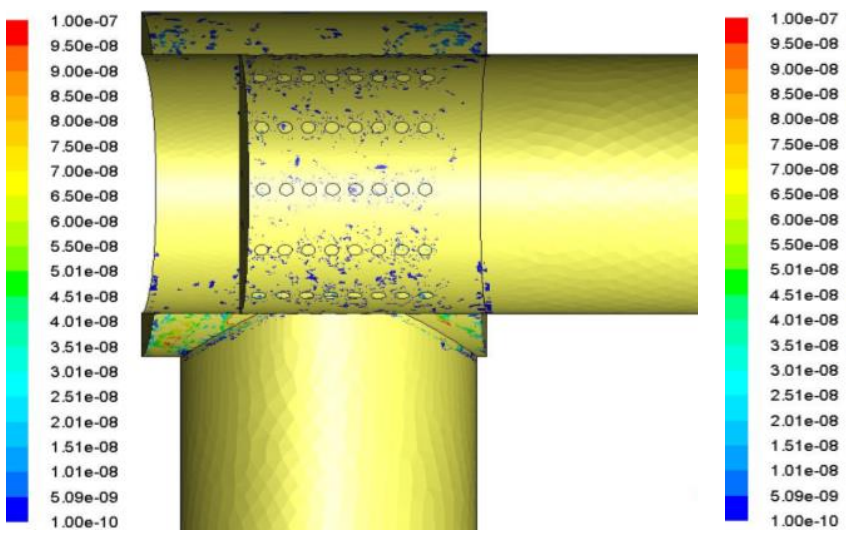

(e) valve opening $80 \%$

(f) valve opening $100 \%$

Figure 8. Erosion rate contours with inlet pressure of $3000 \mathrm{kPa}$ and sand flow rate of $10^{-5} \mathrm{~kg} / \mathrm{s}$.

\section{CONCLUSIONS}

The present study is carried out to investigate the effect of the governing parameters on the sand erosion in a crude oil flow through choke valve. CFD analyses were performed for different valve opening and operating conditions. The simulations in the present study were performed by solving the fluid dynamics field followed by particle tracking and finally erosion rate calculation. Parametric instigation is carried out to calculate the erosion rate for different values of the valve opening, sand flow rate and the pressure difference. The simulation results show that the erosion rate is relatively high value for small valve opening as well as large valve opening. Minimum erosion rate is found when the valve opening is between $20-30 \%$, which is recommended for minimum erosion in the system. The present results show that reduction of both crude oil velocity and sand flow rate results in a decrease in the rate of erosion. Therefore, reduction of the crude oil flow is one way for reducing the 
sand erosion. It is observed that locations with high values of erosion rates are experienced high particles impact velocity with high angle of impingement relative to the main flow direction. Zones affected by sand erosion rate are observed near the valve holes and piston edge. Maximum erosion rate is found in the zone where the valve is connected with the inlet pipe. The current findings can be utilized by oil and gas production and processing companies as a guide of sand erosion in choke valves design and operation.

\section{ACKNOWLEDGEMENTS}

The author wish to thank the anonymous referees. Their comments led to substantial improvements of the original manuscript. The author would like to thank Universiti Teknologi Brunei for providing the facilities for the research work. The author wish to acknowledge the help form the student Siti Nadhirah Haji Mohd Zain in getting the valve picture.

\section{REFERENCES}

[1] Suriani MJ, Nik WBW, Mansor F, Jarkoni MNK, Maizurah CW, Izwani I. Corrosion behavior and resistance parameters of silicon carbide nanocomposite coating on different metals. Journal of Mechanical Engineering and Sciences. 2018; 12: 32883301.

[2] Abu Bakar A, Mohd Ali MKF, Md Noor N, Yahaya N, Ismail M, Abdullah A. Biocorrosion of carbon steel by sulfate reducing bacteria consortium in oil and gas pipelines. Journal of Mechanical Engineering and Sciences. 2017; 11: 2592-2600.

[3] Meng HC, Ludema KC. Wear models and predictive equations: Their form and content. Wear. 1995; 181-183: 443-457.

[4] Okonkwo P, Mohamed AMA. Erosion-Corrosion in oil and gas industry: A review. International Journal of Metallurgical \& Materials Science and Engineering. 2014; 4: 7-28.

[5] Parsi M, Najmi K, Najafifard F, Hassani S, McLaury BS, Shirazi SA. A comprehensive review of solid particle erosion modeling for oil and gas wells and pipelines applications. Journal of Natural Gas Science and Engineering. 2014; 21: 850-873.

[6] Wang J, Shirazi SA. A CFD based correlation for erosion factor for long-radius elbows and bends. J Energy Resour Technol. 2003; 125: 26-34.

[7] Mazumder QH, Siamack AS, Brenton SM. Prediction of solid particle erosive wear of elbows in multiphase annular flow-model development and experimental validations. J Energy Resour Technol. 2008; 130:023001-02300-10.

[8] Elsaadawy E, Papini M, Al-Sherik AM. Solid particle erosion in a partially closed ball control valve. Saudi Aramco Journal of Technology. 2013; 70-77.

[9] Forder A, Thew M, Harrison D. A numerical investigation of solid particle erosion experienced within oilfield control valves. Wear. 1998; 216: 184-193. 
[10] Wallace MS, Dempster WM, Scanlon T, Peters J, McCulloch S. Prediction of impact erosion in valve geometries. Wear. 2004; 256: 927-936.

[11] Paggiaro R, Friedemann JD, Gharaibah E, Zhang Y. Prediction of sand erosion in choke valves - CFD model development and validation against experiments. Offshore Technology Conference, number OTC-24271-MS. 2013.

[12] Rodi W. Turbulence models and their application in hydraulics. Delft International Institute for Hydraulic Research. 1980.

[13] Shih TH, Liou WW, Shabbir A, Yang Z, Zhu J. A new $k-\varepsilon$ eddy-viscosity model for high Reynolds number turbulent flows - model development and validation. Computers Fluids. 1995; 24: 227-238.

[14] Menter FR. Two-equation eddy-viscosity turbulence models for engineering applications. AIAA Journal. 1994; 32: 1598-1605.

[15] ANSYS Inc. ANSYS FLUENT User's Guide. Southpointe, 275 Technology Derive, Canonsburg, PA 15317. 2011.

[16] Morsi SA, Alexander AJ. An investigation of particle trajectories in two-phase flow systems. J. Fluid Mech. 1972; 55: 193-208.

[17] Edwards JK. Development, validation, and application of a three dimension, CFDbased erosion prediction procedure. PhD Thesis, the University of Tulsa, Tulsa. 2000.

[18] ANSYS, Inc. Modeling and Meshing guide, Southpointe, 275 Technology Derive, Canonsburg, PA 15317. 2009.

[19] Moshfeghian M. Effect of chemical additive on crude oil pipeline pressure drop, http://www.petroskills.com/blog, June 2015.

[20] Chala GT, Sulaiman SA, Japper-Jaafar A, Wan Abdullah WAK. Study on influence of flow rates on voids in waxy crude oil subjected to dynamic and static cooling. Journal of Mechanical Engineering and Sciences. 2015; 9: 1587-1594.

[21] Patankar SV. Numerical heat transfer and fluid flow. McGraw-Hill, New York. 1980.

[22] Cengel YA, Cimbala JM. Fluid mechanics: fundamentals and applications, McGrawHill. 2006.

[23] Mazumder QH. S-bend erosion in particulated multiphase flow with air and sand. The Journal of Computational Multiphase Flows. 2016; 8: 157-166. 